\title{
UNA NOTA SOBRE EL ARTICULO 106.2 DE LA CONSTITUCION: EL «CASO PRESTIGE» Y ALGUNAS REFLEXIONES SOBRE LA EVENTUAL RESPONSABILIDAD DE LA ADMINISTRACION ESPAÑOLA
}

\author{
Ricardo de Angel Yágüez \\ Catedrático de Derecho civil de la Universidad de Deusto
}

Sumario: I. Propósito. II. Hipótesis (que por ahora adopto como premisas) sobre los «momentos críticos» que condujeron al hundimiento del Prestige y sobre posibles responsables de los daños producidos. III. El naufragio del buque Lamoricière y las curiosas sentencias del Tribunal de Casación francés. IV. El apartado 2 del artículo 106 de la Constitución y su desarrollo legislativo. «Fuerza mayor», «estado de la ciencia» y relación de causalidad.

\section{Propósito}

El llamado «caso Prestige» está todavía lleno de incógnitas. Por eso, es muy arriesgado aventurar opiniones sobre cualquiera de los muchos problemas jurídicos que pueden resultar de tan lamentable accidente marítimo.

De ahí que en el presente trabajo me limite a examinar algún aspecto de esas posibles cuestiones jurídicas. Lo hago a la luz del apartado 2 del artículo 106 de la Constitución y de las normas que lo han desarrollado, pensando en el caso (hipótesis) de que algún día tuviera que ventilarse la eventual responsabilidad de alguna Administración pública española ${ }^{1}$.

La mención de nuestra Carta Magna, por cierto, es particularmente adecuada en un trabajo como éste, destinado sobre todo a formar parte de una publicación en merecido homenaje al constitucionalista Profesor Lucas Verdú.

${ }^{1}$ En efecto, no cabe descartar que la cuestión pudiera plantearse respecto a «algunas» — más de una— de las Administraciones de nuestro país. 


\section{Hipótesis (que por ahora adopto como premisas) sobre los «momentos críticos» que condujeron al hundimiento del Prestige y sobre posibles responsables de los daños producidos}

A) Habida cuenta de que algunos extremos sobre el cómo y el porqué del accidente ${ }^{2}$ están todavía rodeados de un cierto «misterio», y de que las opiniones «técnicas» sobre sus diversos episodios distan de ser pacíficas $^{3}$, mis siguientes reflexiones se formulan sobre la base de unas «premisas» que, en rigor, lo son sólo a efectos dialécticos o, como suelen decir los juristas franceses, «por exigencias del razonamiento». En otras palabras, en realidad son, por ahora, puras hipótesis.

Para desgranar esas premisas-hipótesis me baso en la que me parece que es una interpretación autorizada de los hechos ocurridos ${ }^{4}$.

Los datos mueven a pensar que en el desarrollo de los sucesos que condujeron al hundimiento del Prestige hubo tres «momentos críticos», sobre los que casi con toda seguridad girará la controversia jurídica en el futuro.

1. Un primer momento fue la súbita y fortísima escora del buque. Los tripulantes oyeron un fuerte ruido y advirtieron que inmediatamente el buque comenzaba a escorarse con gran rapidez a la banda de estribor. Parece poco dudoso que el ruido fue ocasionado por una importante ruptura del casco del buque por esa banda de estribor, que permitió el ingreso a bordo de una gran cantidad de agua.

Cruz Iturzaeta ${ }^{5}$, después de descartar como causa la colisión con el Prestige de un contenedor, o de un gran tronco de madera, o de una sección de tubería, así como la hipótesis de que el boquete fuera originado por una explosión, parece inclinarse por la interpretación de que la chapa del casco del buque se desprendiera por las líneas de soldadura.

Por «exigencias del razonamiento», como antes decía, voy a adoptar como premisa esta interpretación. No obstante, hago notar que,

${ }^{2}$ Expresión ésta (el cómo y el porqué) que tan frecuente es en los razonamientos del Tribunal Supremo sobre relación de causalidad en el Derecho de daños.

${ }_{3}$ Basta recordar las muy dispares que nos han ofrecido los medios de comunicación. Acaso algunas de ellas estén movidas por algún interés, como suele ocurrir en grandes catástrofes y como de hecho ha sucedido en casos de enormes contaminaciones marinas por vertido accidental de hidrocarburos.

${ }^{4}$ Me refiero al artículo de E. CRUz ITURZAETA, «La catástrofe del Prestige. Una versión más amplia, meses después (I)», en la revista Estudios Empresariales, núm. 11, 2003/1, pp. 24-44. El autor es capitán de la Marina Mercante y Licenciado en Ciencias Físicas. Fue Subdirector General de Seguridad Marítima y Prevención de la Contaminación, de la Dirección General de la Marina Mercante.

5 Op. cit., pp. 36-38. 
como luego se dirá, a las mismas conclusiones llegaría si se partiese de otra posible causa del momento inicial al que ahora me refiero.

El mismo autor sugiere que, de haber sido así las cosas, la responsabilidad recaería en el «Estado de bandera», esto es, "Commonwealth of Bahamas», pues, según los Convenios internacionales aplicables, la responsabilidad de que sus buques sean seguros y no contaminantes es, precisamente, del Estado de bandera.

Ahora bien, esta eventual responsabilidad de Bahamas podría concurrir con otras responsabilidades. Téngase presente que siniestros por vertidos de hidrocarburos al mar dan lugar muy frecuentemente a variadas concurrencias como las que en seguida me ocuparán. Esos acontecimientos suelen ser de una dilatada duración y suelen poner en juego muchos y muy diversos protagonismos. Basta recordar que casos como el del Prestige han planteado, tanto en pleitos como en acuerdos extrajudiciales, la eventual responsabilidad de figuras tan variadas como las siguientes: el capitán del buque, su propietario, su armador, el Estado de abanderamiento, el Estado de puerto, el astillero o constructor de la nave, el asegurador del buque, el dueño de la mercancía y su asegurador, la Administración pública, la sociedad de clasificación, la empresa de salvamento o remolque y el FIDAC (a este último me referiré más adelante).

a) Recuperando el hilo de mi exposición, esto es, en relación con el caso del Prestige, viene en seguida a la mente la posible responsabilidad de su propietario ${ }^{6}$. Sería de aplicación, con todas las reservas (en más y en menos, por así decirlo) el Convenio internacional sobre responsabilidad civil nacida de daños debidos a contaminación por hidrocarburos, esto es, el que se suele identificar como CLC/92 ${ }^{7}$.

En aplicación del CLC/92, el propietario el buque respondería sobre la base de una strict liability (responsabilidad objetiva), aunque atenuada por existir las excepciones del artículo III ${ }^{8}$.

No parece que el propietario del Prestige pueda acudir a la excepción a), pues las circunstancias atmosféricas y marítimas del primer día del proceso $^{9}$ no eran tales, según los expertos, que permitan hablar de

\footnotetext{
${ }^{6}$ Me desentiendo ahora de la dualidad propietario-armador, que podría ser de interés a otros efectos.

7 Es el Protocolo de 27-11-92, al que España se adhirió por Instrumento de 6-6-95, BOE del 20-9-95, núm. 225/1995.

8 Vid. J.L. Gabaldón García y J.M. Ruiz Soroa, Manual de Derecho de la navegación marítima, 2. ${ }^{\mathrm{a}}$ ed., Madrid-Barcelona, 2002, pp. 719 ss.

${ }_{9}$ El día 13 de noviembre de 2002. El buque se hundió el 19.
} 
fuerza mayor en su sentido de «fenómeno natural de carácter excepcional, inevitable e irresistible».

Tampoco parece que el propietario pueda alegar la excepción c), esto es, la de que el daño fue causado totalmente por la negligencia $\mathrm{u}$ otro acto lesivo de cualquier Gobierno u otra autoridad responsable del mantenimiento de faros u otras ayudas a la navegación.

El régimen de responsabilidad del propietario, según el CLC/92, tiene carácter exclusivo y excluyente. Exclusivo, porque no puede efectuarse ninguna reclamación contra el propietario salvo de acuerdo con el propio CLC. Y excluyente, porque no pueden ejercitarse acciones en reclamación de indemnización contra los dependientes del propietario, los miembros de la dotación, el práctico, cualquier fletador o arrendatario del buque o cualquier persona que hubiere efectuado operaciones de salvamento.

Por este motivo, prescindo aquí de la posible responsabilidad del capitán del buque, que creo que es en la que inmediatamente pensamos en casos como el del Prestige.

No me ocupo de esta figura, la del capitán, precisamente por las previsiones del CLC. Ahora bien, eso no quita para que su responsabilidad penal pudiera ser declarada por la jurisdicción correspondiente, si bien la civil habría de seguir los cauces del propio CLC, esto es, en el sentido de declararse, incluso en caso de condena penal del capitán, la responsabilidad civil directa, objetiva y limitada del propietario ${ }^{10}$.

Situación diferente sería aquella en la que la responsabilidad civil del propietario del buque quedara fuera del ámbito del CLC, en virtud de las causas de exclusión de responsabilidad que en él se contemplan o — quizá también - como consecuencia de haber perdido el propietario su privilegio de limitación de dicha responsabilidad.

En todo caso, la posible responsabilidad civil del capitán del buque no parece ser en la práctica muy significativa, en atención a que los perjudicados buscan responsables solventes (deep pockets).

Volviendo a la responsabilidad civil del propietario del buque en el CLC, su carácter objetivo, aunque atenuado, se ve «compensado» con una limitación cuantitativa de la indemnización.

En el caso del Prestige, suscita interés la pregunta de si su propietario no tendría derecho a limitar su responsabilidad, en función de lo que dispone el párrafo 2 del artículo $\mathrm{V}$ del CLC. El propietario del buque pierde ese derecho «si se prueba que los daños ocasionados por

10 No es lo que se resolvió por la Audiencia española en el caso del Aegean Sea, buque partido cerca de La Coruña en 1992, con 15.000 toneladas de crudo vertidas al mar. 
contaminación se debieron a una acción o omisión suyas, y que actuó así con intención de causar esos daños, o bien temerariamente y a sabiendas de que probablemente se originarían tales daños ${ }^{11}$.

Es posible especular sobre si el hipotético desprendimiento de una chapa de la banda del buque fue consecuencia de una tan mala vigilancia del barco, por parte de su propietario, que permita afirmar que en su conducta omisiva hubo temeridad y conocimiento (en el sentido de lo que debió haber conocido) de que «probablemente» ocurriría lo que de hecho sucedió.

b) Si se entendiera aplicable el régimen de responsabilidad del CLC, entraría igualmente en juego la llamada responsabilidad del «Fondo internacional de indemnización de daños causados por la contaminación por hidrocarburos», conocido por FIDAC.

Esta entidad, dotada de personalidad jurídica y patrimonio propios, deriva de un Convenio internacional de 1971, modificado luego en 1976 y 1992. España se adhirió al Protocolo de 1992 mediante Instrumento de 6-6-95, BOE de 11-10-97, número 244. Se le conoce habitualmente como FUND/92.

El FIDAC se nutre de las aportaciones de la industria petrolífera y tiene por finalidad la de suplir o complementar la responsabilidad de los propietarios de buques en aquellos casos en que, bien no sean aquéllos responsables conforme al CLC, bien resulten ser insolventes, o bien cuando la suma límite de responsabilidad pagadera por dichos propietarios sea insuficiente para atender en su totalidad los daños causados.

Como bien dicen Gabaldón García y Ruiz Soroa ${ }^{12}$, no parece posible acogerse a ningún principio jurídico para fundamentar esta responsabilidad indirecta de los cargadores o receptores de los cargamentos de crudo. El interés de la industria petrolífera es insuficiente para fundar un principio de responsabilidad civil en sentido propio. Por eso, es más correcto catalogar este fondo suplementario de resarcimiento de daños como un esquema al margen de la responsabilidad civil en sentido estricto, de forma parecida a lo que sucede con otro tipo de fondos o mecanismos de finalidad resarcitoria organizados y mantenidos por la Administración (por ejemplo, el Fondo de Garantía Salarial).

11 Hago notar una circunstancia que me intriga: el texto en español dice «temerariamente y a sabiendas». La conjunción copulativa «y», en vez de una disyuntiva «o», parece implicar una especial cualificación de la temeridad, pero como forma de ésta. Pongo de manifiesto que lo mismo ocurre en el texto en inglés, en el que se dice: «or recklessly and with knowledge that such damage would probably result».

12 Manual ...., cit., pp. 724-726. 
El FIDAC es frecuentemente demandado y condenado en accidentes como el del Prestige. Por eso, es de suponer que su responsabilidad entrará también en liza en este último caso ${ }^{13}$.

c) La misma hipótesis (la del desprendimiento de la chapa), o cualquier otra que revele incumplimiento de las exigencias de la normal navegabilidad del buque, permitiría razonar sobre otras posibles alternativas de responsabilidad, en su caso concurrentes.

Por ejemplo, sugeriría la eventual responsabilidad de la sociedad de clasificación del Prestige, que era American Bureau of Shipping (ABS). Siendo ABS la sociedad a la que Bahamas había delegado su obligación de verificar las condiciones de seguridad del buque ${ }^{14}$, no me parece desechable la tesis de la responsabilidad compartida de ABS, de acuerdo con los criterios dominantes en materia de responsabilidad profesional ${ }^{15}$.

De hecho, el Reino de España ha entablado demanda contra ABS ante el Tribunal de Distrito del Sur de Nueva York, en reclamación de indemnización por daños. La base de la demanda se encuentra en lo que, según resulta del entrecomillado, tiene la apariencia de ser un texto de la propia $\mathrm{ABS}$, en el que se dice que su misión es servir el interés público, así como las necesidades de sus clientes, promoviendo la seguridad de la vida, de la propiedad y del medio ambiente natural, sobre todo por medio del desarrollo y verificación de normas para el diseño, construcción y mantenimiento operativo de servicios marítimos. En el suplico de la demanda se solicita una indemnización estimada en al menos 700.000 dólares USA, además de daños punitivos por la temeraria y deliberada conducta de $\mathrm{ABS}^{16}$.

13 Teniendo en cuenta, además, que el FUND/92 recoge sólo parte de las exoneraciones de responsabilidad que asisten al propietario del buque, por lo que puede suceder que en algún caso no responda el propietario y sí el FIDAC. De otro lado, la indemnización asumida por el FIDAC tiene también un límite cuantitativo.

${ }_{14}$ Los Estados de bandera pueden delegar esta obligación en una sociedad de clasificación, pero no su responsabilidad. La última inspección anual del Prestige, bajo la supervisión y aprobación de ABS, tuvo lugar en mayo de 2002, en Dubai (Emiratos Arabes Unidos).

15 En el caso del buque Amoco Cádiz, 1978, el Consejo de las Costas del Norte, francés, demandó a la sociedad de clasificación, que también había sido ABS (y parece que hubo algún acuerdo transaccional entre las partes).

16 En los apartados 79 a 83 de la demanda se alega que ABS es responsable respecto al Reino de España, al haber llevado a cabo aquélla sus servicios de clasificación sin un cuidado y diligencia razonables o al emitir la clasificación y certificación del buque cuando ABS supo o debió haber sabido que el Prestige no estaba en condiciones de transportar la carga de fuel oil pesado. Se añade que ABS supo o debió haber sabido que el buque no reunía las condiciones que permitieran llevar a cabo el transporte con seguridad. Se dice también que $\mathrm{ABS}$ incumplió su deber de razonable cuidado al permitir que el buque cargase el 
No obstante, ABS ha formulado reconvención en ese juicio; en términos, todo ello, que imagino que pronto verán la luz en publicaciones jurídicas ${ }^{17}$.

Tengo referencias de una demanda entablada también contra ABS, en este caso por parte del Gobierno Vasco y ante el Tribunal del domicilio de ABS, aunque carezco de documentación al respecto.

d) No es tampoco descartable la responsabilidad del astillero constructor del Prestige, aunque parece poco verosímil si se tiene en cuenta que su construcción data de 1976. Sin embargo, de no mediar tan largo plazo, esa responsabilidad puede tener fundamento, en tanto en cuanto el buque fuera defectuoso desde su origen. Es lo que se resolvió en el pleito seguido a resultas del caso Amoco Cádiz ${ }^{18}$, en el que se condenó,

fuel oil y saliese del puerto en condiciones que ABS sabía o debió haber sabido que no eran seguras y adecuadas. Se concluye que el incumplimiento de la obligación de cuidado razonable, por parte de ABS, fue la «causa próxima» de los daños sufridos por el demandante.

17 ABS invoca las «numerosas acciones equivocadas» que se adoptaron por el Reino de España, empezando por su decisión de rehusar el requerimiento del capitán del buque y la recomendación de la empresa de salvamento de proveer un lugar de refugio y/o de llevar el buque a aguas seguras. Por eso, se alega que el Reino de España incurrió en conducta intencional, errónea, temeraria y gravemente negligente para prevenir la polución y para limpiar el fuel oil derramado, así como para prevenir o disminuir cualquier daño a sus ciudadanos y a los ciudadanos del mundo. La reconvención de ABS pide la declaración de que el Reino de España es total o principalmente responsable de todos los daños derivados del Prestige, por lo que debe indemnizar a ABS y/o a contribuir al pago de los daños que en cualquier juicio puedan ser atribuidos a ABS en el mundo, incluidos los que asumieron los Gobiernos y cualquier otra entidad gubernamental, o los ciudadanos, de Francia, Portugal, Reino Unido y España.

18 Mis referencias a otros siniestros parecidos al del Prestige se basan sobre todo en algunos de los siguientes trabajos: J.L. AzCARraga Bustamante, «Algunas reflexiones en torno al siniestro del Torrey-Canyon», Anuario Hispano Luso Americano de Derecho internacional, 1967, pp. 165 ss., I. ARROYO MARTínEZ, «The Aplication of the International Convention on Civil Liability for Oil Pollution Damage to the Urquiola Case», Lloyd's Maritime and Commercial Law, 1977, pp. 337 ss., S. HERnÁNDEZ IZAL, «La responsabilidad del propietario del buque en el supuesto de contaminación marina por hidrocarburos», Revista Jurídica de Catalunya, 1994, pp. 137 ss., J.L. GABALDÓN GARCíA, «Análisis de algunos casos concretos de responsabilidad marítima y su limitación: Amoco Cádiz, Haven, Aegean Sea», VI Jornadas de Derecho Marítimo de San Sebastián, Vitoria, 1999, pp. 221 ss., M. Castillo Daudí, «El siniestro del buque Aegean Sea y la indemnización de los daños», Anuario de Derecho Marítimo, vol. XVIII, 2001, pp. 261 ss. Sobre el caso Exxon Valdez, R. De ANGel YÁGÜEZ, «Derecho y medio ambiente», Ciencias humanas y sociedad: la Fundación Oriol-Urquijo, Madrid, 1993, pp. 263 ss. Puede consultarse también M. OLIVENCIA RUIZ, «Responsabilidad por contaminación marina» en Derecho marítimo, dentro de la colección Cuadernos de Derecho judicial, Madrid, 1993, pp. 89 ss. Una verdadera antología de «casos» sobre la materia puede encontrarse en Z. OYA ÖZÇAYIR, Liability for oil pollution and collisions, Londres- Hong Kong, 1998. 
junto al llamado «grupo Amoco», el constructor naval denominado Astilleros Españoles S.A. ${ }^{19}$

e) Siguiendo la misma línea de hipótesis (y casi ninguna parece rechazable a priori), cabría argumentar incluso sobre la eventual responsabilidad de la empresa que entre abril y mayo de 2001 realizó, en China, importantes reparaciones del buque, a flote y en dique seco.

f) Y en la misma dirección, aunque aquí la hipótesis es todavía menos fundada, según los datos que poseemos, podría ir la alegación de responsabilidad a cargo de la empresa que remolcó al buque ${ }^{20}$.

g) Por fin, y aunque quizá llevando las cosas demasiado lejos, cabe preguntarse sobre la eventual responsabilidad del Estado de puerto, en tanto en cuanto fue en San Petersburgo donde el Prestige hizo su último cargamento y donde las autoridades de puerto ejercieron el derecho que les otorga la legislación nacional e internacional al efecto e inspeccionaron el buque, no encontrando deficiencias de importancia para impedir su salida al $\operatorname{mar}^{21}$. Sería interesante examinar, pero no es ésta la ocasión, el problema en torno a la posible responsabilidad del Estado que inspecciona y no ordena la paralización del buque, existiendo motivos (razonablemente perceptibles) para hacerlo ${ }^{22}$.

2. Me refiero ahora al segundo momento del episodio del Prestige.

Se trata de lo que pudo acontecer en las todavía hoy oscuras «negociaciones» sobre el posible salvamento del buque y su remolque, en los primeros días a partir del 13 de noviembre.

19 El Tribunal de Illinois no aceptó el argumento planteado en la apelación por Astilleros Españoles, que alegaba ruptura de la relación de causalidad, por entender que la causa próxima del accidente estaba en el mantenimiento y operación del buque por parte de Amoco. Es decir, el Tribunal vino a adoptar la teoría de la equivalencia de las condiciones.

${ }^{20}$ Que yo sepa, no se ha esgrimido ningún argumento al respecto. Pero no se trata de una posibilidad remota: en el caso del Amoco Cádiz, la sentencia absolvió a la empresa de salvamento, pero en un obiter dictum se reconoció una acción de regreso contra ella en favor de la sociedad Amoco.

21 Así lo manifiesta Cruz Iturzaeta, op. cit., p. 26, si bien añade que «es prácticamente seguro que la inspección de San Petersburgo se centrase más en los equipos de seguridad, radio o elementos externos del buque, no en las condiciones estructurales del casco, pues estaba cargando y a flote».

22 Sobre la inspección de puerto, v. J.L. Gabaldón García, «Protección del medio ambiente y evolución de Derecho marítimo», Anuario de Derecho Marítimo, vol. XV, 1998 , pp. 303 ss. 
Cruz Iturzaeta ${ }^{23}$ pone de relieve cómo la Administración española informó a la opinión pública de que las personas a bordo del Prestige obstaculizaron el salvamento del buque. Añade que parecida información se ha visto en los medios de comunicación, sobre entorpecimientos y falta de colaboración de los tripulantes para poner en marcha el motor propulsor del barco. Pero advierte, sin embargo, que los abogados de la defensa del capitán han cuestionado fuertemente esta información de la autoridad española.

Por ello, el autor concluye este apartado diciendo: «Un punto clave para saber lo que realmente pasó sería conocer las instrucciones que Universe Maritime daría al capitán del Prestige, mientras ese armador estuviese pendiente del resultado de sus negociaciones con Smit Tak. Smit Tak estaría negociando frenéticamente con Remolcanosa para usar el Ría de Vigo, que a su vez lo haría con Sasemar, según lo antes expuesto. Mientras no se llegase a un acuerdo, es de suponer que Universe Maritime ordenase al capitán que no aceptase ninguna ayuda de salvamento que no estuviese dentro de los términos de un contrato. La voluntad propia del capitán sería muy posiblemente la contraria, aceptar la primera ayuda que se le brindase, pero es seguro que cumpliría las instrucciones de su armador. Habrá que esperar - años - a que los tribunales digan lo que judicialmente sucedió» ${ }^{24}$.

El cabal conocimiento de lo que ocurrió durante esos días (u horas) podría ser jurídicamente significativo a efectos de excluir la limitación cuantitativa de la responsabilidad del propietario del buque (el antes citado artículo V del CLC/92), en tanto en cuanto se acreditase que ese propietario actuó «temerariamente» durante las negociaciones sobre el salvamento o el remolque del buque, y «a sabiendas» de que «probablemente» ocurriría lo que en definitiva vino a acontecer.

Y es también un momento sobre el que podrían aducirse eventuales responsabilidades de la Administración española, de ser cierto lo que alegan los abogados del capitán del buque.

3. Viene, en fin, el tercer momento, el que más ha ocupado la atención de los medios de comunicación.

Me refiero a la decisión de la Administración española de alejar el buque de la costa, esto es, de no remolcarlo a un puerto.

23 Op. cit.,p. 40.

${ }^{24}$ Procede recordar que Universe Maritime era el armador del buque. Smit Tak es una empresa holandesa de salvamento, contratada por el armador para el salvamento del Prestige. Sasemar es el acrónimo de Sociedad Estatal de Salvamento y Seguridad Marítima, que depende de la Dirección General de la Marina Mercante. La empresa Remolcanosa es propietaria del remolcador de salvamento «Ría de Vigo». 
En este punto, desde luego, el juego de las hipótesis sube de tono, viendo como vemos los profanos en Física y en Náutica que las opiniones de los expertos, reales o presuntos, se encuentran divididas ${ }^{25}$.

Naturalmente, yo no voy a emitir ningún juicio. Me limito a señalar algo que más adelante desarrollaré, esto es, el significado que la polémica puede tener a efectos de la causa de exención de responsabilidad que se conoce como «estado de la ciencia».

Se trata, en todo caso, del momento en el que más sentido podría tener la alegación de una eventual responsabilidad de la Administración española. Téngase en cuenta que, por lo que sabemos a través de los medios de comunicación, la defensa del capitán del buque (o de su propietario, o de su armador, que a estos efectos es lo mismo) argumenta que la decisión de la autoridad española de llevar el buque mar adentro fue un novus actus interveniens, esto es, una conducta determinante de la ruptura de la relación de causalidad entre la (siempre supuesta) culpa del capitán, o la del propietario, o la del armador, y lo ocurrido en último término (grandes cantidades de fuel oil pesado en el mar, contaminación de las costas, daños a los pescadores —en el sentido más amplio de esta palabra-, etc.).

La doctrina del novus actus interveniens, si bien no desconocida por la dogmática del civil Law, podría insertarse, aunque no con total exactitud, en la construcción de la causalidad adecuada, tan invocada por nuestro Tribunal Supremo. Siguiendo el modo de argumentar de la defensa del capitán del buque, o de su propietario, la causa adecuada de la fractura y posterior hundimiento del Prestige fue, aun aceptando dialécticamente la inicial culpa del capitán, la decisión de la autoridad española de no llevar el buque a un puerto (ahora prefiero decirlo de este modo).

En la terminología de la «imputación objetiva», esa decisión de la Administración española encajaría en la causa de no imputación que conocemos como «prohibición de regreso». Según ella, no es imputable el daño cuando en el proceso causal que lo antecede, si bien ha sido puesto en marcha por el demandado, se ha encadenado sobrevenidamente la

25 No puedo dejar de señalar, sin embargo, por ser mi fuente de información a otros efectos, que CRUZ ITURZAETA, op. cit., pp. 40-42, parece mostrarse contrario a la operación de meter el Prestige en puerto, de la que dice que «presentaba más interrogantes que seguridades», aduciendo argumentos al respecto. Y debe indicarse también lo que afirma en uno de los fragmentos de su texto: «No sólo esto, la historia de accidentes de este tipo, las apreciaciones de los riesgos, los elementos de juicio profesional independiente, siempre han conducido a la decisión de alejar los buques con este riesgo lo más posible de las costas. La legislación internacional, en concreto el Convenio Intervención, del que son parte Bahamas y España, concede el derecho a los países a tomar medidas, como el alejamiento, para evitar que buques de otros países contaminen sus costas». 
conducta dolosa o muy gravemente imprudente de un tercero, salvo que dicha conducta se haya visto significativamente favorecida por la actuación del demandado ${ }^{26}$.

Traigo a la memoria, al referirme a este extremo, no necesariamente a su calificación jurídica, lo ocurrido en el caso del buque $U r$ quiola, que naufragó en la ría de La Coruña en 1976. A consecuencia de aquel siniestro se siguieron dos pleitos, uno promovido por la viuda del capitán del barco y el otro por las compañías aseguradoras del buque, en reclamación de las cantidades que decían haber pagado a los perjudicados en cumplimiento de las correspondientes pólizas. En este segundo procedimiento recayó sentencia de la Sala Tercera del Tribunal Supremo de 6-5-85, en la que se declaró que la causa exclusiva del naufragio había sido el funcionamiento anormal del servicio público de cartografía y de información, del Instituto Hidrográfico de la Marina, en relación con la existencia de una «aguja» o roca situada dentro del Canal Este de entrada al puerto de La Coruña y que no figuraba en las cartas náuticas editadas por el mentado Instituto.

Esta declaración de responsabilidad se había hecho ya en la sentencia de 18-7-83, de la Sala Cuarta, entonces de lo Contencioso-administrativo, del Tribunal Supremo. En esta sentencia, la recaída en la reclamación de la viuda del capitán, se consideró hecho probado que las autoridades del puerto de La Coruña habían dado orden de ciabogar en el Canal y salir a alta mar. Se declara probado también que el informe de peritos ingenieros navales, obrante en el expediente administrativo, entendió que la operación de ciaboga y salida a alta mar fue "precipitada, desacertada, absurda y criticable».

Es de suponer que algo parecido se alegará en el caso Prestige.

B) No parece necesario explayarse acerca de los daños que podrían reclamarse en este caso.

Ateniéndonos sólo al CLC/92, cuyos criterios al respecto se encuentran también en algunos ordenamientos o doctrinas jurisprudenciales nacionales, es claro que son indemnizables los daños materiales ocasionados por la contaminación a cualquier clase de bienes, sean públicos o privados; entre otros, los gastos de limpieza de otras embarcaciones o de las costas. Tampoco es dudoso que tengan que ser indemnizados los daños patrimoniales derivados de la pérdida de uso de cualesquiera bienes, así como de la imposibilidad de realizar actividades

26 Así, en la síntesis de L. DíEz-PicAzo y A. Gullón, Sistema de Derecho civil, II, 9. a ed., Madrid, 2001, p. 550. 
económicas que con anterioridad se llevaban a cabo. También tendría cabida el llamado «daño ecológico puro», esto es, el deterioro del medio ambiente marino como consecuencia de la contaminación; este capítulo, según el CLC, se limita «al costo de las medidas razonables de restauración efectivamente tomadas o que vayan a adoptarse». Así mismo, la indemnización incluiría el costo de las llamadas «medidas preventivas», esto es, las medidas razonables adoptadas por cualquier persona, después de ocurrir el siniestro, para prevenir o minimizar los daños por contaminación.

La experiencia de siniestros parecidos nos ofrece una amplia información. En el caso del Amoco Cádiz ${ }^{27}$, por ejemplo, demandaron el Estado francés y la entidad, también francesa, Consejo de las Costas del Norte, por los daños experimentados en el litoral de Francia. También lo hicieron empresarios y pescadores de aquel país.

En el siniestro del Exxon Valdez ${ }^{28}$ demandaron pescadores, empresas de transformación, el Estado de Alaska (tanto como public trustee como parens patriae) y la sociedad ecologista National Wildlife ${ }^{29}$.

Por lo que respecta al accidente del buque Haven, naufragado en 1991 en las costas de Liguria, se formuló reclamación por alrededor de 1.350 víctimas, contándose entre ellas particulares, Administraciones públicas territoriales y el propio Estado italiano. Este último reclamó los daños debidos a operaciones de limpieza y los experimentados por el medio ambiente.

En el accidente del Aegean $\mathrm{Sea}^{30}$ se concedieron indemnizaciones, en la sentencia de la Audiencia de La Coruña, en favor - entre otrosdel Gobierno español, de la Xunta de Galicia, de la ciudad de La Coruña y otras localidades próximas, de criaderos de almejas y mejillones, de pescadores, de mariscadores, de empresas de transformación y transportistas, etc. En algunos casos, se dejó su determinación al trámite de ejecución de sentencia.

En este último episodio, el del Aegean Sea, se dio la interesante circunstancia (alguien podría sugerir que la del caso Prestige, aunque lo

27 En 1978, en la Bretaña francesa.

28 Naufragio frente a las costas de Alaska, 1989.

${ }^{29}$ Como corresponde a las particularidades del sistema jurídico de Estados Unidos, se formularon reclamaciones por daños punitivos. Y también fue un caso muy propicio para la interposición de demandas en régimen de class actions.

30 Vid. CAstillo DAudí, «El siniestro...», cit., sobre todo en su anexo IV. Fueron condenados el capitán del barco y el práctico del puerto, por imprudencia temeraria. Se declaró la responsabilidad civil limitada de ambos. Se declaró así mismo la responsabilidad civil directa y solidaria del asegurador del buque y del FIDAC, del mismo modo que la subsidiaria del propietario del buque y del Estado Español. 
dudo, por lo que luego diré) de que el Estado español fue declarado responsable civil subsidiario por la imprudencia temeraria apreciada en el práctico del puerto que dirigía el buque, al tiempo que fue también considerado perjudicado o víctima, si bien se dejó para ejecución de sentencia la cuantificación de su indemnización. De sus daños respondería el propietario del buque (y también su asegurador y el FIDAC), pero sólo en un $50 \%{ }^{31}$.

Si bien no existen resoluciones judiciales, que yo sepa, sino expedientes administrativos cuyo detalle no se publica, parece que se puede afirmar que en el caso Urquiola el Estado indemnizó a las víctimas de daños económicos (pesca, marisco, etc.), en términos parecidos a los posteriores del Aegean Sea.

\section{El naufragio del buque Lamoricière y las curiosas sentencias del Tribunal de Casación francés}

En 1942 naufragó en el Mediterráneo el buque Lamoricière, pereciendo ahogadas más de 300 personas. Los hechos permitieron establecer que el naufragio fue debido a una tempestad excepcional, verdadero ciclón. También se probó que el carbón del buque era de mala calidad y que ésta había sido una de las causas de la catástrofe, porque si el carbón hubiese sido mejor, la fuerza de las calderas habría permitido superar la tempestad. Por otro lado, la mala calidad del carbón no era imputable a culpa de la compañía de navegación; eran tiempos de guerra y el carbón había sido suministrado por el Estado, que no disponía de otro mejor.

La compañía de navegación fue considerada «guardián» del buque en aplicación del artículo 1.384 del Código civil francés, y se le declaró (inicialmente) responsable por este concepto. La mala calidad del carbón, aunque no le fuera imputable, no podía exonerarle, por ser un hecho de origen interno que impedía estimar un caso de fuerza mayor. Pero el Tribunal de Casación, en dos sentencias de la Sala de lo comercial de 19-6-51, entendió que el ciclón tenía los caracteres de la fuerza

31 Interesa dejar constancia de que otra Administración, la de la Xunta, alegó —y se le reconocieron- daños como los siguientes: gastos de personal para la llevanza de una oficina de reclamaciones, gastos de empleo de helicópteros y de un remolcador, los de la campaña publicitaria para promocionar el consumo del marisco, los de trabajos de cooperación suscritos con la Universidad de Santiago, los de las limpiezas de playas y disposición de residuos, etc. A los ayuntamientos se les reconocieron gastos de policía, bomberos, asistencia social, limpieza de la ría y de las aves de la zona, etc. 
mayor: imprevisible, inevitable y externo. Sin embargo, esto no exoneraba del todo al «guardián».

El Tribunal confirmó el criterio de los jueces de instancia, que habían estimado que la catástrofe había tenido por causa la fuerza mayor en una concurrencia de cuatro quintas partes solamente, correspondiendo al «hecho de la cosa» - el buque- la quinta parte restante. Por tanto, la compañía de navegación fue condenada a pagar una indemnización representativa de un quinto del perjuicio alegado por las víctimas ${ }^{32}$.

Las sentencias del caso Lamoricière dieron lugar a una considerable polémica y a una abundante literatura jurídica, con mayoría de opiniones contrarias a la solución del Tribunal, de la que se dijo que podría considerarse inspirada por sentimientos humanitarios, un poco al margen del Derecho puro ${ }^{33}$.

Hubo en Francia alguna otra sentencia en la misma línea. Por ejemplo, una de 1957, en la que el Tribunal de Casación consideró que cuando quien invoca la fuerza mayor ha cometido también una conducta culposa, de forma que ésta ha contribuido, bien a determinar el suceso, bien a agravar sus consecuencias, el juez puede atenuar la responsabilidad y reducir la cifra de los daños y perjuicios. En aquel caso se trataba de un dique que había sido construido por la sociedad demandada y que impedía el desagüe de las aguas pluviales, circunstancia ésta que en el pleito se consideró que era reveladora de culpa. Al producirse en la región una borrasca de una violencia excepcional, la obra mal hecha provocó una grave inundación en un inmueble situado aguas abajo. El Tribunal de apelación condenó a la sociedad demandada a indemnizar la totalidad del daño, al considerar que, a pesar del carácter excepcional de la borrasca, los daños no se habrían producido si no hubiese existido una construcción culposa. No obstante, como hemos visto, el Tribunal de Casación resolvió de otro modo, con el razonamiento antes resumido por mí.

Si interesan estas citas a efectos de lo que me ocupa en este trabajo, es porque el caso Prestige podría ser sugestiva manifestación de un

32 Vid. H. y L. Mazeaud y A. Tunc, Tratado teórico y práctico de la responsabilidad civil delictual y contractual, ed. argentina, t. segundo, vol. II, Buenos Aires, 1963, pp. 225 ss., B. STARCK, Droit civil (obligations), Paris, 1972, pp. 272 ss., y G. VINEY, La responsabilité: conditions, en el Traité de droit civil, de J. GHEstin, Paris, 1982, pp. 485 ss.

33 Así, STARCK, cit., p. 274, que sugiere que los jueces habrían estimado que en realidad el naufragio se había debido a fuerza mayor; pero aventura la opinión de que, habiendo habido más de 300 ahogados, los jueces se las ingeniaron para establecer una ayuda a quienes sufrían, material y moralmente, como consecuencia de la pérdida de uno de los suyos. 
problema de gran interés dogmático: la solución que procede cuando la fuerza mayor concurre con la culpa del demandado a la realización del perjuicio ${ }^{34}$.

Señalaba antes que soluciones como la del caso Lamoricière fueron muy discutidas en la doctrina francesa y rechazadas por su mayoría, pero dejo planteado el problema, cuyo desarrollo merece debida atención.

No obstante, procede dejar constancia, por ejemplo, de la opinión de Mazeaud y Tunc ${ }^{35}$, cuando dicen: «En resumen, la fuerza mayor, cuando es la única causa del daño, libera siempre íntegramente al demandado. Pero, si la culpa de este último ha concurrido con un fenómeno natural a la realización del perjuicio, la víctima tiene derecho a una reparación parcial».

Por lo que respecta a la doctrina española, destaco la opinión de Díez-Picazo y Gullón ${ }^{36}$, que escriben: «Problema arduo se presenta cuando el caso fortuito o fuerza mayor concurre con una conducta del agente que merece reproche de culpabilidad. Creemos que entonces debe examinarse si aquel caso o fuerza hubiera producido el mismo resultado dañoso sin la conducta del mismo, y si la contestación es afirmativa, quedaría liberado éste de toda responsabilidad, igual que si el daño es ocasionado por la nueva causa, aunque la conducta del agente pudiera haberlo producido si no se hubiera interrumpido la relación de causalidad. Si el caso o la fuerza viene a agravar el resultado de la conducta del agente, deben ser tratados como concausas y éste no debe responder de todo, sino de la parte que le corresponde, lo que en la práctica se traduce en una moderación del quantum indemnizatorio».

\section{El apartado 2 del artículo 106 de la Constitución y su desarrollo legislativo. «Fuerza mayor», «estado de la ciencia» y relación de causalidad}

A) Sabemos lo que dice el apartado 2 del artículo 106 de la Constitución: «Los particulares, en los términos establecidos por la ley, tendrán derecho a ser indemnizados por toda lesión que sufran en cualquiera de sus bienes y derechos, salvo en los casos de fuerza mayor, siempre que la lesión sea consecuencia del funcionamiento de los servicios públicos».

\footnotetext{
34 Como diré más adelante, quizá sea necesario distinguir entre fuerza mayor y fenómeno de la naturaleza o causa extraña.

35 Op. cit., p. 229.

36 Sistema.... Ahora, la cita es sobre su 8. ${ }^{\text {a }}$ ed., Madrid, 2000, pp. 536-537. En la 9. ${ }^{\text {a }}$ edición, Madrid, 2001, el epígrafe de relación de causalidad tiene una nueva configuración.
} 
Sabemos así mismo que, en desarrollo de dicha norma, los artículos 139-144 de la Ley de régimen jurídico de las Administraciones Públicas y del procedimiento administrativo común (LAPPA), de 26-11-92, reguló la responsabilidad de las Administraciones Públicas y de sus autoridades y demás personal a su servicio, sobre las siguientes bases:

-Artículo 139.1: «Los particulares tendrán derecho a ser indemnizados por las Administraciones Públicas correspondientes, de toda lesión que sufran en cualquiera de sus bienes y derechos, salvo en los casos de fuerza mayor, siempre que la lesión sea consecuencia del funcionamiento normal o anormal de los servicios públicos» ${ }^{37}$.

-Artículo 141.1: «Sólo serán indemnizables las lesiones producidas al particular provenientes de daños que éste no tenga el deber jurídico de soportar de acuerdo con la Ley».

Somos así mismo conscientes de que un sector de la doctrina ${ }^{38}$ se preguntó qué significa la responsabilidad de la Administración por el funcionamiento normal de las Administraciones Públicas, paliando las extravagantes consecuencias a las que conduciría la interpretación literal del precepto.

Y, por fin, no se oculta a nadie el significado que puede tener la reforma del apartado 1 del artículo 141 de la LAPPA, operada en virtud de la Ley de 13-1-99, de modificación de la mentada LAPPA.

Conviene recordar lo que ahora dice esa norma: «Sólo serán indemnizables las lesiones producidas al particular provenientes de daños que éste no tenga el deber jurídico de soportar de acuerdo con la Ley. No serán indemnizables los daños que se deriven de hechos o circunstancias que no se hubiesen podido prever o evitar según el estado de los conocimientos de la ciencia o de la técnica existentes en el momento de producción de aquéllos, todo ello sin perjuicio de las prestaciones asistenciales o económicas que las leyes puedan establecer para estos casos».

Con independencia del juicio que pueda merecer la incorporación a la Ley de la exención de responsabilidad de la Administración cuando se trate de daños derivados de «hechos o circunstancias que no se hubiesen podido prever o evitar según el estado de los conocimientos de

37 No puedo dejar de recordar el críptico o misterioso significado de las palabras de la exposición de motivos de aquella Ley, al decir que «el proyecto da respuesta al pronunciamiento constitucional de indemnización de todas las lesiones que los particulares sufran en sus bienes y derechos como consecuencia del funcionamiento de los servicios públicos».

38 Sobre todo, F. PANTALEón PRIETO, Responsabilidad médica y responsabilidad de la Administración, Madrid, 1995. 
la ciencia o de la técnica existentes en el momento» de producción de tales daños ${ }^{39}$, lo que conviene retener es que esa exención se produce en dos casos (al menos): el de fuerza mayor, al que se refieren el artículo 106.2 de la Constitución y el artículo 139 de la LAPPA, y el descrito en las palabras entrecomilladas que preceden.

Por eso, ambas causas de exención, en lo que se refiere al caso Prestige, deben ser objeto de análisis separado.

B) La Administración Pública no responde «en los casos de fuerza mayor», según acabamos de ver.

1. Llevado esto al accidente de nuestro buque, cumple en primer lugar analizar cuáles eran las circunstancias meteorológicas del primer día del proceso y de la jornada en que el buque se partió y hundió.

Manteniéndome en la versión de Cruz Iturzaeta ${ }^{40}$, el 13 de noviembre había un fuerte temporal de viento del oesnoroeste y mar de fuerza 8 (de una escala de 0 a 10), es decir, el viento y las olas ejercían un fuerte efecto transversal al buque por estribor. Más adelante, el mismo autor ${ }^{41}$ considera que en sus 26 años largos de navegación, es seguro que el Prestige tuvo que navegar y soportar fuertes temporales de viento y mar. El mal tiempo dominante en el momento del accidente - añade- no tuvo calificación de extraordinario, pues fue de fuerza 8 , con olas de unos 7 metros de altura. Este tipo de buques — continúa Cruz Iturzaetase suele diseñar para soportar sin dificultades olas de una altura de hasta un 5\% de su eslora, es decir, olas de unos 12 metros de altura. Por lo que concluye que «no parece lógico "culpar" del accidente al mal tiempo».

Por cierto, la utilización del verbo «culpar» por parte del citado autor me recuerda lo que escribí en un trabajo en torno al significado de las palabras «responder» y derivadas. Me trae a la mente un pasaje particularmente agudo de Hart, en el que este jurista trabajaba con el juego de palabras que éstas permiten. Propone Hart el siguiente texto ficticio: «Como capitán del barco, X era responsable por la seguridad de sus pasajeros y carga. Pero en su último viaje se embriagaba todas las noches

39 No me parece muy afortunado el pasaje de la exposición de motivos de la Ley de 13-1-99, cuando dice que «en el 141 se matizan los supuestos de fuerza mayor que no dan lugar a responsabilidad». Creo que la causa de exención a la que se refiere ese preámbulo no es tanto una «matización» de los supuestos de fuerza mayor, sino una circunstancia que afecta a la antijuridicidad o ilicitud del daño, sin que pueda desconectarse tampoco — en algunos casos al menos - de la relación de causalidad. Pero ésta es una cuestión que debe tratarse por separado y en otro lugar, sin perjuicio de lo que luego diré.

40 Op. cit., p. 33.

${ }^{41}$ P. 36. 
y fue responsable por la pérdida del barco con todo lo que llevaba. Se rumoreaba que estaba loco, pero los médicos lo encontraron responsable de sus acciones. Durante el viaje, $\mathrm{X}$ se comportó muy irresponsablemente; y varios accidentes, que tuvo en su carrera, demostraron que no era una persona responsable. El capitán siempre sostuvo que fueron las tormentas excepcionales las responsables de la pérdida del barco, pero en un proceso judicial que se le siguió fue encontrado responsable por la pérdida de vidas y bienes. Todavía vive y es moralmente responsable por la muerte de muchas mujeres y niños» ${ }^{42}$.

Después de este inciso, vuelvo al Prestige.

Supuestas las circunstancias atmosféricas del día 13 de noviembre, no tengo datos precisos sobre las de los días en que se produjo la decisión administrativa de llevar el buque mar adentro, o de los anteriores o posteriores. Por eso, tengo que razonar en torno a una situación parecida a la del día 13, aunque ligeras modificaciones no alterarían el curso y el desenlace de mis reflexiones.

2. Centrado nuestro interés en la eventual responsabilidad de la Administración española, al decidir que el Prestige fuera remolcado mar adentro, el artículo 106.2 de la Constitución y el 139.1 de la LAPPA obligan a determinar si en el caso concurrió o no fuerza mayor.

Lo que nos lleva a la difícil cuestión de si la fuerza mayor es un concepto diferente del caso fortuito (y, en su caso, cuáles son sus diferencias) y a la no menos compleja de si el concepto de fuerza mayor debe entenderse de la misma manera en la responsabilidad contractual que en la extracontractual.

Habría que dejar de lado en seguida, porque no viene a cuento, la hipótesis de responsabilidad contractual, puesto que no hablamos de la que podría haber contraído el armador del Prestige respecto al dueño de la mercancía transportada. Nos referimos a una eventual responsabilidad (la de la Administración española) que sería, en términos tradicionales, extracontractual o aquiliana, al no existir ningún deber de prestación previo entre esa Administración y aquel propietario del fuel oil.

En el ámbito de la responsabilidad contractual, y aunque el artículo 1.105 del Código civil ofrece muchas posibilidades (por ejemplo,

42 El texto de Hart está en el ensayo o capítulo IX, titulado Postscript: Responsibility and Retribution, en su libro Punishment and Responsibility. Essays in the Philosophy of Law, Oxford, 1984, pp. 210-267. Mi trabajo citado es R. DE Angel YÁGüEZ, «Sobre las palabras "responder", "responsable" y "responsabilidad"», Estudios de Deusto, vol. 50/1, enero-junio 2002, pp. 11 ss., pendiente de publicación en el Libro Homenaje al Profesor Luis Díez-Picazo y Ponce de León. 
la de distinguir sólo entre sucesos previsibles e inevitables), viene teniendo acogida la diferencia propuesta en su día por Exner, y basada en la diversidad entre acontecimientos internos y externos a la actividad normal o natural del deudor. Sin mucha convicción personal, según parece, Díez-Picazo y Gullón ${ }^{43}$ exponen: «Aunque la línea dominante en la jurisprudencia es la no distinción del caso fortuito con la fuerza mayor en cuanto a los efectos, no ha dejado de hacerse eco de la diferenciación doctrinal de ambos eventos, y que ve el caso fortuito como el acontecimiento que tiene lugar en el interior de la empresa o círculo afectado por la obligación, mientras que la fuerza mayor sería el que se origina fuera, con violencia insuperable, y que cae fuera de lo que debe preverse en el curso ordinario y normal de la vida».

De seguirse este criterio de distinción del que acabo de hacer mención, no parece defendible que en el comienzo del proceso del Prestige concurriera una situación calificable como fuerza mayor. Me remito a lo dicho antes sobre las circunstancias meteorológicas del día 13 de noviembre, que no tienen las trazas de ser representativas de algo extraordinario, fuera de lo común o excepcional. Más aún, cabe pensar que lo ocurrido aquel día fue un riesgo interno de la navegación marítima. No cabe sino seguir la opinión de $\mathrm{Starck}^{44}$, cuando, refiriéndose al caso Lamoricière, opina que un mar embravecido no debería nunca considerarse como un elemento «externo» en relación con la navegación marítima, porque el mar es uno de los elementos necesarios en ella.

Pero, como apuntaba antes, quizá no quepa hablar de fuerza mayor en cualquier ámbito de la responsabilidad civil; en concreto, respecto a acontecimientos como el del Prestige.

$\mathrm{Al}$ desarrollar casos como el del Lamoricière, Mazeaud y Tunc ${ }^{45}$ los rotulan con el epígrafe «la fuerza mayor concurre con la culpa del demandado a la realización del perjuicio», pero advirtiendo que más exacto que hablar de fuerza mayor es decir un fenómeno natural ${ }^{46}$. Y quizá por

43 Sistema..., 9. ${ }^{\mathrm{a}}$ ed., cit. p. 201.

44 Droit civil, cit., p. 274.

45 Tratado ..., cit., p. 225.

46 En concreto, los autores escriben: «La cuestión se plantea en iguales términos si se ve en la fuerza mayor un hecho imprevisible e irresistible o la contrapartida de la culpa. En ambos casos, en verdad, la expresión de la fuerza mayor es impropia y no se debería hablar sino de "acontecimiento natural". En efecto, resulta claro que el hecho no era imprevisible e irresistible, puesto que ha podido surtir su efecto tan sólo por una culpa del demandado; y que no era tampoco, en la otra concepción de la fuerza mayor, el hecho que excusa al demandado de haber participado en la realización de un daño y que demuestra el carácter puramente pasivo de esa participación». 
el mismo motivo, Viney ${ }^{47}$ distingue entre concurrencia del hecho imputado al demandado con «causa extraña que no presenta los caracteres de fuerza mayor», atribuyendo a esto último la denominación de «caso fortuito», en el sentido de circunstancias exteriores y fortuitas, aunque previsibles y vencibles. Entre ellas, no duda en incluir el caso Lamoricière.

$\mathrm{Y}$ es posible que, por el mismo motivo, Díez-Picazo opte por utilizar la expresión «caso fortuito» para refundir los supuestos del artículo 1.105 del Código civil ${ }^{48}$. El autor se inclina por referirse, genéricamente, a «causas extrañas» al deudor, esto es, eventos o hechos exteriores que queden fuera del ámbito o marco de control del deudor. Por eso, al referirse a los fenómenos y eventos naturales, Díez-Picazo los considera «ejemplos de los más claros y manifiestos casos fortuitos» (si bien con las oportunas reservas).

3. Trasladándonos ahora de forma inequívoca al mundo de la responsabilidad extracontractual ${ }^{49}$, procede, a mi juicio, formular alguna observación a partir de todo lo anterior.

En primer lugar, creo que no puede atribuirse el mismo significado al estado de la mar en el primer día del proceso del Prestige (respecto a su dueño o a su capitán, por ejemplo) que al del día en el que se tomó la decisión de alejar el buque (por tanto, en lo que hace a la Administración española).

Suponiendo que las circunstancias marítimas fueron las mismas, parece oportuno insistir en que aquéllas constituían un riesgo natural de la navegación, aunque fuera de carácter sobrevenido; quiero decir, aunque la situación fuera mejor en los días anteriores.

Esto es, el capitán no podría alegar que «el mar se había embravecido», para así descargar su responsabilidad.

Pero creo que no es la misma la valoración en lo que respecta a la Administración. Para ésta, las condiciones meteorológicas del momento en cuestión constituían un estado de cosas que le venía dado. Es decir, se trataba de un presupuesto de su actuación (la orden de alejamiento del buque).

Para la Administración, aquel estado de cosas revestía, a mi juicio, un innegable carácter «externo».

${ }^{47}$ La responsabilité...., cit., pp. 485-486.

48 L. DíEz-PiCAzo, Fundamentos del Derecho civil patrimonial, vol. segundo, 5. ${ }^{\text {a ed., }}$ Madrid, 1996, pp. 588 ss.

49 No sin advertir que el criterio de distinción entre lo interno y lo externo se encuentra también en este terreno, como resulta del artículo 1 de la Ley sobre responsabilidad civil y seguros en la circulación de vehículos a motor, al no considerar casos de fuerza mayor «los defectos del vehículo ni la rotura o fallo de alguna de sus piezas o mecanismos». También se hallaba presente en el artículo 1.784 del Código civil. 
Podría decirse, en segundo término, que no fue un suceso imprevisible, porque es evidente que, en abstracto, entra dentro de lo previsible que un buque llegue a las proximidades de las costas de un país en la forma y en el estado en los que lo hizo el Prestige.

Pero creo que no carece de fundamento decir que la circunstancia de que el hipotético buque llegue en efecto (el Prestige o el que fuera) es, en lo que se refiere a la Administración (que no es un naviero), un verdadero «hecho de la naturaleza».

Quiere decir, por tanto, que a efectos de la Administración no cabe hablar sólo del estado de la mar o el viento, sino del conjunto del escenario: el temporal que había y el buque como estaba.

A mi entender, otra interpretación sería absurda, porque conduciría al resultado de que a una Administración marítima nada que pueda suceder le es imprevisible.

Y todavía mayor enjundia tiene razonar sobre el «requisito» de inevitable. Me parece obligado determinar de qué hablamos cuando usamos este adjetivo.

Por coherencia, no puedo decir inevitable para referirme sólo al temporal, al estado de la mar o al viento. Es razonable que lo inevitable se juzgue en función del estado de cosas al que vengo aludiendo, esto es, no sólo las circunstancias atmosféricas, sino ellas y el estado en el que el Prestige se encontraba.

Es tentador decir que lo evitable fue lo que ocurrió luego (esto es, el hundimiento del buque, el derrame de hidrocarburo y los daños que todos conocemos), pero esto, en mi opinión, sería una perversión dialéctica, porque implicaría tener resuelta de antemano la pregunta sobre si haber ordenado (o permitido) el remolque del buque a un puerto habría evitado lo que como desenlace ocurrió.

Es por esto por lo que, según creo, lo relativo a las circunstancias de la naturaleza en sentido estricto (el temporal, en suma) no entraña particular significado en lo que respecta a la responsabilidad o no responsabilidad de la Administración actuante.

Quiero decir que el conjunto al que antes me he referido (el temporal que había y el buque como estaba) no constituye en sí mismo - es decir, por sí solo- material suficiente para razonar en torno a la causa de exención que es la llamada «fuerza mayor», sino que es el antecedente para especular sobre si la Administración podría verse exonerada de responsabilidad a la luz de la segunda de las causas que al efecto establece el artículo 141 de la LAPPA.

Expresado de otro modo, considero que razonar en torno a la fuerza mayor no lleva a ningún sitio en el caso en el que nos encontramos, a efectos del artículo 106.2 de la Constitución y del 141.1 de la LAPPA, 
porque, en el propósito de enjuiciar la acción de la Administración, el estado de cosas del día «X» (el conjunto del que vengo hablando) no fue un suceso sobrevenido respecto a una acción previa de esa Administración, sino la realidad sobre la que esta última tenía que operar.

Lo que significa, a mi juicio, que es necesario examinar si la decisión de la autoridad administrativa se halla o no cobijada en la otra causa de exención de responsabilidad.

C) Hablo, claro está, de la constituida por el segundo inciso del tan citado artículo 141.1 de la LAPPA (daños derivados de hechos o circunstancias «que no se hubiesen podido prever o evitar según el estado de los conocimientos de la ciencia o de la técnica existentes en el momento de producción» de tales daños) ${ }^{50}$.

No es dudoso que estas palabras de la Ley reflejan lo que comúnmente conocemos como «estado de la ciencia»o, en expresión de los juristas norteamericanos, «estado del arte» ${ }^{51}$. Es decir, algo parecido, aunque no necesariamente idéntico, a lo que también denominamos «riesgos del desarrollo».

El concepto de «estado de la ciencia», como es sabido, se acuñó en el terreno de la product liability, esto es, de la responsabilidad civil por daños derivados de productos defectuosos. Refleja la idea de que el fabricante puede ser eximido de responsabilidad si los conocimientos científicos y técnicos existentes en el momento de puesta en circulación de un producto no eran los mismos que los que luego se tuvieron ${ }^{52}$. Y así se ha recogido en la Ley española sobre la materia, de 6-7-94, trasladando lo previsto por la Directiva comunitaria de $25-7-85^{53}$.

50 Sobre la distinción entre ciencia y técnica, v. la sentencia de la Sala Tercera de 31-5-99.

${ }^{51}$ Por todos, J. GonZÁlez Pérez, Responsabilidad patrimonial de las Administraciones públicas, 2. ${ }^{a}$ ed., Madrid, 2000, pp. 351 ss., y F. LóPEZ MENUdo, «Responsabilidad administrativa y exclusión de los riesgos del progreso. Un paso adelante en la definición del sistema», Derecho y Salud, vol. 8, julio-diciembre 2000, pp.1 ss.

52 Por todos, v. J. Stapleton, Product Liability, Londres, 1994, y C. Hodges, Product liability. European laws and practice, Londres, 1993. No entro en la cuestión, irrelevante en el caso Prestige, de si el desconocimiento del concreto fabricante tiene o no que ver con lo que podría esperarse de un fabricante de productos análogos (en el sentido de que este último sí habría podido descubrir el defecto): J. LETE ACHIRICA, «Los riesgos de desarrollo en materia de responsabilidad por los daños causados por productos defectuosos. Comentario a la sentencia del Tribunal de Justicia de las Comunidades Europeas de 29 de mayo de 1997», Actualidad Civil, núm. 28, 13-19 de julio de 1998, pp. 685 ss.

53 En el artículo 6.1 de la Ley española se dispone que el fabricante o el importador no serán responsables si prueban «que el estado de los conocimientos científicos y técnicos existentes en el momento en la puesta en circulación no permitía apreciar la existencia del defecto». 
No parece necesario extenderse ahora sobre la justificación de la exención de responsabilidad de la Administración por causa del «estado de la ciencia», aunque comparto la opinión de López Menudo ${ }^{54}$, cuando dice que «si los ciudadanos resultan generalmente beneficiados de la acción prestadora pública, a la que exigen los niveles de calidad propios del moderno estado de la ciencia o de la técnica, asumiendo así sus riesgos, no es disparatado afirmar que aquéllos vengan obligados a soportar, en el plano jurídico, los eventuales daños generados por hechos producidos en un momento histórico en el que era invencible la ignorancia sobre sus efectos lesivos».

El hecho es que, volviendo al caso Prestige, la defensa de la Administración española tendrá que argumentar sobre este concepto de «estado de la ciencia».

Si es cierto (hipótesis) que la ciencia náutica —expresión con la que quiero significar lo que imagino que es un conjunto de saberes que van desde la Física hasta la Mecánica - no permite hoy afirmar con razonable seguridad lo que procede hacer en situaciones como las concurrentes en el acontecimiento que nos ocupa, existiendo también falta de certeza científica plena sobre los posibles efectos nocivos de una acción (la de llevar el buque mar adentro o la de conducirlo a puerto) ${ }^{55}$, creo que encontraría sólido fundamento la defensa de la Administración española.

Dicho de otro modo, en tanto en cuanto fuera cierto que existen dudas científicas (también hipótesis) sobre lo que tenía que haber sido el proceder de la Administración en las circunstancias del Prestige, a la luz del «estado de los conocimientos», sería razonable, a mi entender, defender la decisión de la autoridad española con base en el artículo 141.1 de la LAPPA. Tendría que demostrar — creo que le incumbe el onus probandi- que, en verdad, esa incertidumbre científica existe ${ }^{56}$.

${ }^{54}$ Op. cit., p. 4.

55 Podría tener cabida aquí el llamado «principio de precaución», que en la hipótesis planteada exige la adopción de las precauciones que la prudencia recomienda (artículo 174 de la versión consolidada del Tratado de la Unión Europea). No obstante, como ya he señalado en otro lugar (R. DE ANGEL YÁGÜEZ, «El principio de precaución y su función en la responsabilidad civil», pendiente de publicación en una obra colectiva, Publicaciones de la Cátedra de Derecho y genoma humano, Universidad de Deusto-Universidad del País Vasco), este «principio de precaución» sería de aplicación para la confección de protocolos de actuación ante situaciones similares a las del Prestige, esto es, como fórmula de policy (entendida como «estrategia», «pauta» o «práctica»), pero no como criterio de valoración de responsabilidades ante decisiones ya tomadas.

56 Así lo afirma también la citada sentencia de la Sala Tercera de 31-5-99. 
D) Pero acaso pueda irse más lejos en la argumentación a favor de la Administración española, reflexionando en términos de relación de causalidad.

1. No faltan opiniones que sostienen que la «defensa» basada en el estado de la ciencia tiene que ver con el concepto de fuerza mayor. Según hemos visto antes, adopta este criterio la propia exposición de motivos de la Ley de 13-1-99, de modificación de la LAPPA. También lo consideró así la sentencia de la Sala Cuarta de 3-12-99, dictada en un caso de inoculación de virus de hepatitis $\mathrm{C}$.

Sin embargo, la concepción tradicional de la fuerza mayor llevaría a conclusión diferente, puesto que esa noción supone un acontecimiento que ocurre ex post facto, de naturaleza externa, y por tanto fuera del control del eventual responsable; mientras que, en el caso del «estado de la ciencia», la circunstancia así llamada se encuentra, como tal fenómeno, dentro de la esfera de actividad —distíngase del control- del hipotético responsable ${ }^{57}$.

Suele argumentarse que «estado de la ciencia» y fuerza mayor no son lo mismo, porque en la Directiva comunitaria sobre productos defectuosos, antes citada, la segunda no está formulada como causa de exención de responsabilidad del fabricante, y sí en cambio la primera. Pero esta razón no me parece convincente, pues siempre cabe decir que el «estado de la ciencia» es una modalidad de la fuerza mayor. Esto, sin contar con otros argumentos que ahora no proceden.

Es innegable que el «estado de la ciencia» tiene cierto parecido con la fuerza mayor. Así opina Bercovitz ${ }^{58}$, al considerar que hay una «ruptura de nexo causal entre conducta del productor y existencia del defecto por un supuesto similar a la fuerza mayor: la imposibilidad de descubrir - y, consecuentemente, subsanar- el defecto».

Pero, puestos a precisar más, y sin menospreciar la idea de que se trata de un caso en el que el particular tiene el deber jurídico de soportar el daño (con el inconveniente de que, vistas así las cosas, la reforma de 1999 sobre el texto originario de la LAPPA quedaría en este punto

57 GonzÁlez PÉrez, op. cit., p. 354, dice que «parece evidente que el supuesto no puede catalogarse entre los de fuerza mayor», a cuyo efecto cita la doctrina de la ya referida sentencia de la Sala Tercera de 31-5-99. De forma menos «comprometida», este autor acude al concepto de «titulo de imputación», argumentando que ese título —el riesgo creado por la Administración- no existe cuando se trata de un «riesgo permitido». Y en este último capítulo incluye el estado de conocimiento de la ciencia y de la técnica.

58 R. BERCOVITZ RodRígueZ-CANO, «La responsabilidad de los fabricantes en la Directiva de las Comunidades Europeas de 25 de julio de 1985», Estudios sobre consumo, núm. 7, abril 1986, p. 294. 
desprovista de contenido), parece fundada la tesis de que la causa de exención que nos ocupa es una causa de justificación o de no antijuridi$\operatorname{cidad}^{59}$.

No obstante, creo que no cabe descartar que los hechos constitutivos de una hipótesis de «estado de la ciencia» puedan también tener significado a efectos de la relación de causalidad.

Desde luego, parece claro que es así si se contempla la relación de causalidad desde la perspectiva clásica de la condicio sine qua non. Así lo pone de relieve, indirectamente, Pantaleón Prieto ${ }^{60}$, cuando dice:

«La fórmula de la condicio sine qua non —nos dicen, sobre todo sus contradictores - no aprehende inmediatamente la relación de causalidad, sino que la presupone lógicamente. Porque sólo cuando se sabe ya que existe un nexo causal entre una determinada condición y el resultado, puede afirmarse que, sin la condición, dicho resultado no se habría producido. Cuando, por el contrario, se desconoce la virtualidad causal de la condición en cuestión respecto del resultado, el procedimiento de supresión mental no puede proporcionarnos ninguna luz sobre si aquélla ha tenido o no algún influjo sobre éste. Los famosísimos casos de la talidomida constituyen un buen ejemplo de lo que quiere decirse: si no sabemos previamente si, en el caso concreto que se juzga, la talidomida ha tenido o no influencia en las malformaciones del feto (éstas pueden ser exclusivamente debidas a otras causas), nada podrá decirnos la fórmula criticada sobre la existencia o no de relación de causalidad entre la toma de la talidomida y las citadas malformaciones. Sólo cuando se ha establecido previamente si la droga ha tenido o no influencia en la producción del evento lesivo, puede utilizarse con sentido la (ya sólo útil a efectos de control lógico a posteriori) fórmula de la condicio sine qua non».

Adoptando este punto de vista, podría decirse que toda relación causal se basa en lo cognoscible, esto es, en lo que se sabe a ciencia cierta que va a suceder. Aplicado esto, por ejemplo, a la responsabilidad por productos defectuosos, se diría que al tiempo del lanzamiento del producto al mercado no existe un nexo de causalidad «ajustado a la ley de la experiencia científica», precisamente porque cuando se elaboró aquél, el estado de la ciencia y de la técnica no permitía formular ninguna «ley científica» al respecto.

59 Me convence la interpretación de LóPEz MENUdo, op. cit., en su conjunto.

60 F. PANTAleón PRIETO, «Causalidad e imputación objetiva: criterios de imputación», Centenario del Código civil, II, Madrid, 1990, pp. 1561 ss., concretamente 1562, en este pasaje. 
Aplicado esto al caso Prestige, se diría que la Administración española adoptó una decisión que, aunque se entendiera no amparada por ninguna «ley de experiencia científica», tampoco se encontraba desautorizada por otra de las mismas características. Y aquí, siempre dentro de la hipótesis de «duda», se da la particularidad (hipótesis) de que no se ha llegado a un conocimiento científico o técnico que después ha acreditado que el modo de actuar anterior fue contrario o simplemente distinto del que tenía que haber sido. Esto, a diferencia de lo que ocurre con los ejemplos académicos en materia de daños derivados de productos defectuosos, en los que a posteriori se conoce la existencia del defecto.

2. Pero, como apuntaba antes, no me parecería infundado que la Administración española se defendiese en sede de relación de causalidad, sobre la base de los mismos hechos en que se ampararía la «defensa» fundada en el «estado de la ciencia».

Debo insistir en el matiz: el elemento común a ambas argumentaciones serían unos determinados hechos, los ocurridos, no - como es obvio - su interpretación dogmática.

Al comienzo de este trabajo decía que una eventual demanda contra una Administración española encontraría cobijo en la doctrina del novus actus interveniens. Es decir, dentro de lo que en la doctrina continental europea conocemos como relación de causalidad.

Pues bien, situándonos precisamente en ese terreno es cuando podría acudirse a las construcciones, más o menos tradicionales, sobre la puesta a cargo de alguien que la relación de causalidad entraña.

Y para formular una interpretación al respecto, no con otro motivo, me atengo al criterio de la imputación objetiva.

Sin entrar en detalles sobre la doctrina así llamada, es razonable pensar que una eventual demanda contra la Administración española, si procediese del propietario del buque, podría inspirarse - ya lo decía también al principio- en el criterio de no imputación conocido como «prohibición de regreso». Aun admitiendo a efectos dialécticos la culpa del propietario del buque, o de su capitán, se negaría la imputación objetiva y el daño a cualquiera de ellos, porque en el proceso causal dañoso se incardinó sobrevenidamente la conducta dolosa o muy gravemente imprudente de un tercero. Recordémoslo: la decisión de la Administración española de conducir el buque mar adentro.

Ahora bien, se da la paradójica circunstancia de que también la Administración española podría acogerse a la relación de causalidad para fundar su no responsabilidad. 
Porque, en efecto, no parece necesario insistir mucho en dos ideas:

- De un lado, en que la relación de causalidad es elemento inexcusable para que exista responsabilidad ${ }^{61}$. Cualquiera que sea el criterio de imputación (la culpa, el riesgo, la objetiva producción del daño, la equidad, etc.), no se responde si no puede ponerse a cargo del demandado el daño por el que se reclama. Y eso es razonar en el plano de la relación de causalidad. Y es por eso por lo que no se produce en materia de relación de causalidad ningún tipo de presunción, y tampoco inversión de la carga de la prueba ${ }^{62}$.

-De otra parte, es patente que una argumentación jurídica basada en la relación de causalidad exige — valga la forma de hablartodavía más precisión cuando se trata de una responsabilidad calificada de objetiva, cual es la de la Administración en el Derecho español. Los detalles, los matices, en definitiva el análisis dotado de un mayor rigor, son los que permiten - razonando en sede de relación de causalidad-limar las asperezas de una responsabilidad objetiva y, por ende, evitar soluciones absurdas, extravagantes, y aun esperpénticas, a las que de otro modo podría conducir ese tipo de responsabilidad, pero mal entendida ${ }^{63}$.

Volviendo a nuestro caso, la Administración española imaginariamente demandada ${ }^{64}$, podría defenderse razonando, incluso (otra paradoja), en el terreno de la causa de no imputación objetiva que conocemos como «prohibición de regreso»; esto es, la misma que en principio podría soportar la pretensión del demandante.

Sin necesidad de repetir una sintética formulación de lo que se entiende por «prohibición de regreso» (pues me remito a la que antes he utilizado, tomándola de Pantaleón Prieto ${ }^{65}$ ), este criterio de no imputación objetiva no se entendería bien, ni sería razonable, si no fuera con la puntualización que el mismo autor expresa, ajustándose a lo que la doctrina dominante opina.

61 Evidentemente, hablo de una responsabilidad civil, la de la Administración. Sigo rechazando eso que me parece tan raro, de responsabilidad patrimonial.

62 Cosa distinta es que esa carga pueda verse aliviada, en favor del perjudicado demandante. Pero eso será a través de argumentos distintos del concepto de relación de causalidad, argumentos que ahora no vienen a cuento.

63 Acaso pueda residir aquí la explicación de que la doctrina de la Sala Tercera de nuestro Tribunal Supremo en punto a la relación de causalidad sea, en términos generales, de tanta calidad como la que a mi juicio tiene.

64 No es tan imaginario, porque ya lo ha sido, por vía de reconvención, en Estados Unidos, según antes hemos visto.

65 «Causalidad ...», cit., p. 1568. 
Tiene sentido negar la imputación objetiva del daño al demandado cuando, aun habiendo puesto en marcha éste el proceso causal, se ha incardinado sobrevenidamente la conducta dolosa o muy gravemente imprudente de un tercero, «salvo que dicha conducta - sigo palabras del mismo autor - se haya visto significativamente favorecida por la actuación del demandado o, con más claridad, sea una de aquellas que la norma de cuidado infringida tenía la finalidad de prevenir».

Si se enlaza esta idea con lo que antes he venido admitiendo a modo de hipótesis, se me hace difícil admitir que la acción de la Administración española, al ordenar el traslado del buque mar adentro, pueda calificarse de gravemente imprudente. Lo sería si los criterios de diligencia derivados de la experiencia científica (obsérvese que de nuevo regresamos al «estado de la ciencia») permitieran afirmar que aquella decisión fue abiertamente contraria o distinta de lo que esa experiencia científica exige o simplemente recomienda. De no ser así, no me parecería muy fundada una resolución que no imputase la responsabilidad a quien desencadenó el curso causal (otra vez tengo que volver a la hipótesis y razonar como si fuera seguro que quien lo hizo fue el propietario del buque, al ponerlo a la mar sin las debidas condiciones de navegabilidad).

Pero, incluso admitiendo a efectos dialécticos la grave imprudencia de la Administración, el problema sigue en pie.

Creo que es así, porque habría que determinar si la conducta de la Administración se vio «significativamente favorecida» por la inicial actuación del demandado. Me mantengo en la hipótesis de que el demandado fuera el capitán, o el propietario del buque, o incluso la sociedad de clasificación ABS.

Me parece que, al situarnos en este hito del razonamiento, nos encontramos con una circunstancia digna de ponerse de relieve: la de que, aunque hablemos de una responsabilidad de la Administración de carácter objetivo (en la que, por tanto, se prescinde de la culpa), nos vemos obligados a valorar el grado de reprochabilidad de las conductas enjuiciadas ${ }^{66}$.

Es decir, con independencia del criterio de imputación de responsabilidad propio de cada caso, la puesta en juego de la doctrina de la «prohibición de regreso» no sólo permite, sino que obliga, a comparar, contrastar

66 Sería algo parecido, mutatis mutandis, y sin perjuicio de la opinión que pueda merecer el criterio del Tribunal Constitucional en este punto, a lo que él declaró en la sentencia de 29-6-2000, al resolver las cuestiones de inconstitucionalidad planteadas por diversos órganos judiciales sobre determinados extremos de la Ley sobre responsabilidad civil y seguro en la circulación de vehículos a motor, en relación con la cuantificación de los daños personales basada en un sistema de «baremo». Como se recordará, la sentencia utiliza la expresión de culpa relevante. 
o ponderar las conductas concurrentes, a fin de establecer - en lo que ahora nos ocupa - cuándo la actuación de quien puso en marcha el curso causal (en nuestro planteamiento dialéctico, el propietario del buque, pongamos por caso) favoreció significativamente el modo de proceder del sobrevenidamente interviniente (la Administración española).

Pero para seguir razonando en esta línea es necesario saber (incógnita) cuál fue la causa del primer momento en el proceso del Prestige.

Si se tratara de un acontecimiento fortuito (utilizo esta expresión en su sentido más amplio, sólo para querer significar que no hubo culpa de nadie), parece que aquí quedaría sofocada cualquier argumentación de la Administración española basada en lo que vengo diciendo.

Diferente sería la cuestión si se probara que hubo culpa del propietario del buque (insisto en que no es necesario hablar de otros culpables a estos efectos), por no reunir el Prestige las adecuadas condiciones de navegabilidad.

Si se diese esta segunda situación, no creo que fuera carente de fundamento la alegación de la Administración española en el sentido de que la conducta del propietario del buque favoreció de tal manera la decisión de la propia Administración, que esa decisión (novus actus interveniens) no quebró la inicial imputabilidad objetiva de lo ocurrido al propietario desencadenante del curso causal.

En el terreno de una normal valoración de las cosas, creo que un observador neutral (e incluso profano, quiero decir no jurista) no colocaría en el mismo plano de reproche el modo de proceder del propietario del buque (en función de un riesgo que es propio de su actividad, que entraña su lucro y que no encuentra disculpa) que el de la Administración, situada esta última en la tesitura de tomar una decisión urgente, impuesta por las circunstancias, obligadamente atenta a la preservación de intereses que no necesariamente tenían que haberse visto perjudicados (es una incógnita qué podía haber ocurrido si el Prestige hubiera llegado a más distancia de la que alcanzó) y, desde luego, desprovista de ánimo de lucro.

3. Pero, según decía al principio, todo lo anterior no es otra cosa que un conjunto de reflexiones (no tengo inconveniente en llamarlas especulaciones) que, como se ha visto, giran en torno a hipótesis de hecho no verificadas ni comprobadas todavía.

Es una ventaja (mejor dicho, una exigencia) de proposiciones científicas como las que preceden - por muy modestas que sean-, libres de la defensa de cualquier concreto interés. 